\title{
A Corte Exemplar: Considerações sobre a Corte de Warren
}

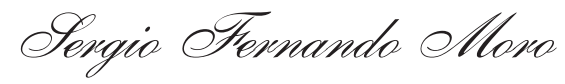

Juiz Federal em Joinville/SC, Mestre e Doutorando em Direito pela Universidade Federal do

Paraná, Autor do livro Desenvolvimento e Efetivação Judicial das Normas Constitucionais.

\section{RESUMO}

Trata da célebre Corte de Warren (19531969), considerada um paradigma para a jurisdição constitucional, com abordagem de suas decisões mais importantes, de sua técnica de decisão e com paralelo, quando possível, com a doutrina e jurisprudência constitucional pátria.

\section{SUMÁRIO}

1 Considerações iniciais;

2 Primórdios;

3 A composição da Corte;

4 Combatendo a segregação racial;

5 Reordenação de distritos eleitorais;

6 Liberdade de expressão e outros direitos preferenciais;

7 Direito de privacidade;

8 Casos criminais;

9 Considerações finais;

Referências bibliográficas.

\section{Considerações iniciais}

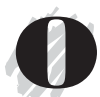

controle judicial de constitucionalidade nasceu nos Estados Unidos da América, com Marbury v. Madison, de 1803. Posteriormente e principalmente após a Segunda Grande Guerra, o controle, com nuances diversas, foi adotado por outros países. $\bigcirc$ pioneirismo norte-americano, bem como a atuação destacada da Suprema Corte daquele país propiciaram, entretanto, intenso debate acerca da jurisdição constitucional, sendo imprescindível para estudo aprofundado desta a referência à experiência norte-americana.

Nessa linha, é também imprescindível referência específica à célebre Corte de Warren, responsável por verdadeira revolução constitucional no período de 1953 a 1969. Sua influência ultrapassa as terras norte-americanas. $\bigcirc$ Direito Constitucional atual, e não somente nos Estados Unidos, mas em todos os países que adotam controle judicial de constitucionalidade, não pode ser compreendido sem referência 
à produção desta Corte. Para o bem ou para o mal, os termos dos debates constitucionais atuais foram estabelecidos por esta Corte.

O propósito do presente artigo é traçar breve panorama sobre a muito citada, mas pouco conhecida entre nós, Corte de Warren, suas decisões e suas técnicas de decisão, traçando, quando possível, um paralelo em relação à prática constitucional brasileira.

\section{Primórdios}

A história da Corte Warren não pode ser adequadamente compreendida sem breve referência ao seu passado próximo. As bases de seus julgados encontram-se na evolução da jurisprudência constitucional norte-americana na primeira metade do século XX.

No início do século, a Suprema Corte norte-americana vivia a época conhecida como a Era Lochner, assim denominada pelo conhecido caso Lochner v. New York, de 1905, na qual invalidou lei do Estado de Nova York que estabelecia limite para a carga horária de trabalho dos empregados de padaria. Destacou-se, nesse período, por seu ativismo judicial conservador. Invalidou, sistematicamente, com base no princípio da razoabilidade e guiada pelo liberalismo econômico então predominante, as nascentes leis de intervenção do domínio econômico, inclusive, as que protegiam os trabalhadores.

Tal postura foi abandonada apenas na década de 30, com julgados como Nebbia v. New York, de 1934, e West Coast Hotel
Co. v. Parrisch, de 1937, após a colisão da jurisprudência da Corte com o New Deal do Presidente FRANKLIN ROOSEVELT.

Passou a Corte a presumir a constitucionalidade de toda legislação de intervenção no domínio econômico, adotando o que se convencionou denominar de rational basis test no controle judicial de constitucionalidade. Para que a lei passasse neste teste bastava que fosse razoavelmente relacionada a um objetivo político válido, o que não se afigura difícil. Na prática, passou a presumir a constitucionalidade de toda a legislação da espécie.

Em caso que se insere nessa nova linha, Carolene Products Co. v. USA, de 1938, o Juiz HARLAN FISK STONE formulou, na célebre nota de rodapé $\mathrm{n}^{\mathrm{O}} 4$, tese de que, em determinadas hipóteses, tal presunção de constitucionalidade da lei poderia ser afastada:

"Pode existir um âmbito mais estreito para utilização da presunção de constitucionalidade quando a legislação aparece, evidentemente, compreendida dentro de uma proibição específica da Constituição, tal como aquelas das dez primeiras emendas, as quais são consideradas da mesma forma quando usadas dentro do contexto da Décima Quarta.

É desnecessário considerar agora se a legislação que restringe estes processos políticos, dos quais ordinariamente se espera que provoquem a repulsa de leis indesejáveis, deve se submeter a um escrutínio judicial mais rigoroso, sob as proibições gerais da Décima Quarta Emenda, do que os outros tipos de legislação.

Tampouco precisamos investigar agora se considerações similares devem 
ser feitas na revisão de leis dirigidas a singulares minorias religiosas, nacionais ou raciais, ou se preconceitos contra minorias discretas e insulares devem constituir uma condição especial, que tende a restringir o funcionamento desses processos políticos nos quais se pode ordinariamente confiar para a proteção das minorias, e que podem exigir uma investigação judicial correspondentemente mais inquiridora." ${ }^{1}$

A doutrina então aventada significava que a Corte passaria a adotar um duplo padrão no exame de constitucionalidade das leis.

Usualmente, presumiria a constitucionalidade da lei, principalmente se de intervenção no domínio econômico pela lembrança da Era Lochner. Se a lei, entretanto, afetasse um direito considerado fundamental, como aqueles previstos nas emendas da Constituição norte-americana, ou se afetasse processos políticos de formação da lei, ou ainda certas minorias, a Corte se serviria de um teste de constitucionalidade mais rigoroso, que convencionou-se denominar strict scrutiny, ${ }^{2}$ no qual a lei, ainda que relacionada a um objetivo político legítimo, seria considerada inválida se o mesmo objetivo pudesse ser alcançado por meio menos gravoso e se este (o objetivo) não fosse qua- lificado como de especial magnitude (compelling public interest).

É oportuno destacar que a Suprema Corte atual ainda serve-se de tal modelo de decisão, existindo ainda um teste de nível intermediário (denominado de intermediate scrutiny, no qual a lei deve ser justificada por um interesse público de especial relevância, que foi, por exemplo, aplicado em Sugarman v. Dougall, de 1973, no qual a Corte admitiu que o Estado poderia estabelecer restrições ao acesso de estrangeiros a cargos públicos estratégicos).

Assim, agindo com base em presunções acerca do funcionamento do processo político democrático, a Corte determina qual espécie de padrão de controle será apropriado para o caso em suas mãos.

Tal teoria fornece base interessante para justificação da jurisdição constitucional frente à democracia. Os inimigos da jurisdição constitucional recorrem normalmente ao argumento de que é necessário resguardar a autonomia popular exercida pelos representantes eleitos do povo contra interferências excessivas de juízes que não foram elevados e nem podem ser destituídos de seus cargos através do voto. Sem embargos de todas as críticas que podem ser feitas a tal argumento, ele perde força quando a ativi-

1 LOCKHART, 1996, p. 18.

2 Em Korematsu v. USA, de 1944, a Suprema Corte americana entendeu que se defrontava com situação da espécie. Julgava a constitucionalidade das medidas restritivas impostas aos nipo-americanos durante a Segunda Guerra Mundial. Apesar da decisão ser absolutamente criticável aos olhos atuais, principalmente porque medidas equivalentes não foram tomadas contra a comunidade de descendentes de alemães ou italianos, é oportuna a transcrição de trecho do raciocínio então adotado: "Todas as restrições legais que limitam os direitos civis de um particular grupo racial são imediatamente suspeitas. Isso não quer dizer que todas essas restrições são inconstitucionais. Quer dizer que as cortes devem submetê-las ao mais rígido escrutínio judicial. Prementes necessidades públicas podem, algumas vezes, justificar a existência dessas restrições; antagonismo racial nunca pode". (LOCKHART, 1996, p. 1.164) 
dade da jurisdição constitucional é justificada em vista do mau funcionamento da democracia e orientada a eliminar obstáculos ao seu ótimo funcionamento.

Não cabem aqui maiores considerações sobre tão intrincado tema, mas destacar apenas que a Corte de Warren fez largo uso da teoria inaugurada em Carolene. Aliás, há quem julgue a jurisprudência da Corte, como seu confesso admirador JOHN HART ELY, ${ }^{3}$ como exemplo de concepção procedimental da jurisdição constitucional, o que, entretanto, pode ser questionado, pois nem todas as decisões da Corte se enquadram nesse específico modelo.

\section{A composição da Corte}

EARL WARREN foi indicado Presidente da Suprema Corte norte-americana em 1953 pelo então Presidente EISENHOWER. Nela atuou até 1969, sendo sucedido por WARREN BURGER, por sua vez indicado pelo então Presidente NIXON.

Quando assumiu seu posto, a Suprema Corte era composta por HUGO
BLACK, WILLIAM DOUGLAS, FELIX FRANKFURTER, TOM CLARK, STANLEY REED, HAROLD BURTON, ROBERT JACKSON E SHERMAN MINTON. FRANKFURTER foi substituído por ARTHUR GOLDBERG em 1962. Por sua vez, este foi sucedido em 1965 por ABE FORTAS. MINTON foi substituído por WILLIAM BRENNAN em 1956. CLARK foi substituído em 1967 por THURGOOD MARSCHALL. REED foi substituído em 1957 por CHARLES WHITTAKER que, por sua vez, foi substituído em 1962 por BYRON WHITE. BURTON foi substituído em 1958 por POTTER STEWART. JACKSON foi substituído em 1955 por JOHN HARLAN.

Historiadores norte-americanos destacam que a Presidência de WARREN pode ser dividida em dois períodos, pois foi somente a partir de 1962, com a substituição do relativamente conservador WHITTAKER por BYRON WHITE e com a substituição de FELIX FRANKFURTER, o principal defensor de postura de restrição da jurisdição constitucional, pelo liberal ARTHUR GOLDBERG, que logrou-se for-

3 ELY, 1995. Primeira edição em 1980. A obra em questão, central à doutrina constitucional norte-americana, merece comentário a parte. ELY questiona as teorias então prestigiadas acerca da jurisdição constitucional, qualificando-as como "interpretativistas" ou "não-interpretativistas". Defende uma terceira opção, segundo a qual a atuação da jurisdição constitucional estaria justificada apenas em caso de mau funcionamento da democracia, ou seja, quando não se justificaria a confiança no processo democrático, hipótese na qual a autoridade judicial estaria melhor posicionada que o legislador para interpretar a Constituição. O processo democrático careceria de confiança quando, em síntese: "a) os que estão dentro estão bloqueando os canais de mudanças políticas para assegurar que eles permaneçam dentro e os que estão fora permaneçam fora, ou b) mesmo que ninguém esteja privado verdadeiramente de voz ou voto, os representantes, de olho na maioria efetiva, estão sistematicamente deixando em desvantagem alguma minoria mantida fora por simples hostilidade ou recusa preconceituosa em reconhecer interesses em comum e, desse modo, privando tal minoria da proteção concedida a outros grupos em um sistema representativo". (ELY, 1995, p. 102-103.). A posição de ELY granjeou vários adeptos e críticos (entre as críticas acessíveis ao leitor brasileiro recomenda-se DWORKIN, 2000, p. 80-100). A ver deste autor, a jurisdição constitucional não deve se limitar às hipóteses de mau funcionamento da democracia. Desde de que demonstrada suficientemente violação da Constituição, o que é possível não somente em casos de mau funcionamento, é legítima a atuação da jurisdição constitucional. Não obstante, a teoria de ELY fornece justificativa aceitável para atuação mais incisiva da jurisdição constitucional em casos nos quais o processo democrático careça de confiança. 
mar uma sólida maioria liberal (liberal no sentido próprio da política norte-americana). A maioria liberal, também composta por BLACK, DOUGLAS e BRENNAN e pelo próprio WARREN, foi ainda reforçada em 1967 com a nomeação de THURGOOD MARSHALL, o primeiro afro-americano a compor a Suprema Corte norte-americana.

De todos eles, merecem especial destaque, além do próprio Chief Justice: a) HUGO BLACK, principal defensor de interpretação estrita do texto constitucional, especialmente da Primeira Emenda; b) WILLIAM DOUGLAS, juiz considerado brilhante e de múltiplos interesses; e c) WILLIAM BRENNAN, por alguns considerado o principal juiz do período pela sua liderança intelectual, não devendo também ser desconsiderado que, após a saída de WARREN, foi ele quem assumiu a liderança da ala liberal.

A figura principal do período, entretanto, foi o próprio Chief Justice. $\bigcirc$ próprio juiz WILLIAM BRENNAN, como visto considerado por muitos como a liderança intelectual da Corte de Warren, reconhecia o papel de Warren, denominando-o, ilustrativamente, de Super Chief. ${ }^{4}$

Segundo BERNARD SCHWARTZ, WARREN não era um scholar como muitos de seus pares na Suprema Corte. No entanto, a história da Suprema Corte, segundo o mesmo autor norte-americano, revelaria que nem sempre os grandes juízes da Suprema Corte foram também grandes juristas e que nem sempre os grandes juristas na Suprema Corte foram também grandes juízes. ${ }^{5}$ WARREN destacava-se por sua visão do papel da Corte na vida norte-americana, que, graças a sua liderança, logrou tornar realidade. Não era um defensor da postura de restrição judicial, mas, ao contrário, apregoava o ativismo judicial principalmente para compensar as deficiências do processo político democrático, conforme pode ser verificado na produção da Corte sob a sua liderança.

\section{Combatendo a segregação racial}

Brown v. Board of Education, de 1954, na qual foi reputada inconstitucional a segregação racial predominante nas escolas públicas no Sul dos Estados Unidos, talvez seja a mais importante decisão da Corte de Warren.

Ilustra ainda o papel essencial da liderança de WARREN.

O caso foi ouvido na Suprema Corte inicialmente sobre a liderança do Chief Justice FRED VINSON que defendia a manutenção do regime segregado. Segundo memorando confidencial do Juiz WILLIAM DOUGLAS, a Corte, por maioria de cinco votos contra quatro, inclinava-se então a favor da segregação. A decisão foi, entretanto, adiada para o ano seguinte. Nesse intervalo, o Chefe VINSON faleceu, sendo substituído por WARREN, que logrou obter a unanimidade entre os juízes para a condenação da segregação, 
reputando-a incompatível com o princípio da igualdade.

Saliente-se que o princípio da igualdade, equal protection of the law, havia sido inserido na Constituição norte-americana pela Décima Quarta Emenda, de 1868, e que os componentes do Congresso de então, que também editava leis para o Distrito de Columbia, no qual ficava a sede do Governo Federal, haviam, na mesma legislatura, adotado regime de escolas segregadas no referido distrito. Portanto, a segregação não era inconstitucional de acordo com a concepção dos autores da emenda. A Corte ainda teve que enfrentar o precedente Plessy v. Ferguson, de 1896, na qual reputou compatível com o princípio da igualdade a segregação nos transportes ferroviários, fazendo-o nos seguintes termos do voto de WARREN:

"Na abordagem deste problema, nós não podemos voltar nossos relógios para 1868 quando a Emenda foi adotada, ou, ainda, para 1896 quando Plessy foi decidido. Nós devemos considerar a educação pública à luz de seu completo desenvolvimento e seu lugar presente no modo de vida americano por toda a $\mathrm{Na}$ ção. Só por este caminho pode ser determinado se a segregação nas escolas públicas priva os reclamantes da igual proteção da lei." 6

WARREN, servindo-se de estudos psicológicos modernos, todos citados na nota de $\mathrm{n}^{\mathrm{o}} 11$ do julgado, defendeu que a doutrina "separados, mas iguais" estabelecida em Plessy não tinha lugar em matéria educacional, pois a simples segregação comprometia o desenvolvimento educacional do grupo segregado:

"Separá-los [as crianças negras] de outros de idade e qualificações similares só em virtude da raça negra gera um sentimento de inferioridade de seu status na comunidade que deve afetar seus corações e mentes de um modo que provavelmente não possa ser desfeito. (...) Qualquer que fosse a extensão dos conhecimentos psicológicos na época de Plessy, essa observação é amplamente amparada pelas autoridades modernas." ${ }^{\text {T }}$

Concluiu então que a segregação na educação era inerentemente desigual.

É oportuno destacar que a Corte não se limitou a reconhecer o direito dos demandantes a ingressarem em escolas reservadas a brancos. Tinham eles direito a escolas em regimes integrados, o que implicava na adoção de larga política pública de dessegregação, afetando, portanto, escolas e alunos não envolvidos diretamente no caso. A dessegregação, segundo a Corte, deveria ser implementada com toda a rapidez deliberada (with all deliberate speed). Tão interessante quanto Brown é a implementação do resultado do julgado, o que provocou inúmeras controvérsias e intervenções nos distritos escolares pelas instâncias inferiores e pela própria Suprema Corte. ${ }^{8}$

8 Como exemplo de todos os casos, é oportuna a referência a Swann v. Charlotte-Mecklenburg Board of Education, de 1971, no qual a Suprema Corte manteve decisão de juiz federal que, dada a recalcitrância das autoridades administrativas em cumprir 
A decisão da Corte ilustra a necessidade: a) de proteção de grupo social e politicamente vulnerável, evocando a referida nota de $\mathrm{n}$ o 4 de Carolene; b) de interpretação evolutiva da Constituição, colocando em dificuldades doutrinas como o "originalismo", então com algum prestígio nos Estados Unidos e segundo a qual a interpretação da Constituição deve ser orientada pela intenção de seus autores; c) de considerar amplamente os fatos envolvidos na decisão constitucional, fazendo uso inclusive de dados fornecidos por ciências não jurídicas.

A partir de Broun, a segregação racial existente em boa parte dos Estados Unidos foi progressivamente erosionada, contribuindo para o movimento dos "direitos civis" norte-americano. ${ }^{9}$ Aliás, decisões da própria Corte culminaram por concluir pela inconstitucionalidade da segregação em estabelecimentos públicos ou abertos ao público e de leis estaduais racistas como a que proibia o casamento inter-racial. ${ }^{10}$

\section{Reordenação de distritos eleitorais}

Em 1962, a Corte de Warren decidiu Baker v. Carr, na qual estava em discus- são a má ordenação de distritos eleitorais no Estado do Tennessee.

Segundo HORWITZ, ${ }^{11}$ nesse tempo, o problema da má ordenação de distritos eleitorais assumia ares de acentuada gravidade nos Estados Unidos pela recusa dos legisladores em redesenhar os distritos mesmo após sensível alteração da distribuição da população no território nacional decorrente principalmente do crescimento dos centros urbanos. No Tennessee, os distritos eleitorais estavam configurados de forma que menos de $40 \%$ da população podia eleger a maioria dos representantes nas assembléias legislativas estaduais. Em onze estados, incluindo a California, a maioria dos senadores estaduais poderia ser eleita por menos de $20 \%$ da população. No que se refere aos deputados estaduais, existiam quatro estados nos quais a maioria poderia ser eleita por menos de $20 \%$ dos votantes.

Em Baker v. Carr, de 1962, a Corte reviu o precedente Colegrove v. Green, de 1949, admitindo que a ordenação dos distritos eleitorais era matéria sujeita à revisão judicial e não mais uma "questão política".

Admitida a possibilidade do controle judicial, a Corte, em Reynolds v. Simms,

Brown, ordenou a implementação de plano de dessegregação elaborado por perito judicial e que envolvia inclusive a modificação do sistema de transporte escolar. A implementação de Brown ilustra a possibilidade de adoção de política pública de certa complexidade através do judiciário, sempre que necessário para remediar situação incompatível com a Constituição.

9 Para uma abordagem completa e crítica recomenda-se CHAMBERS, 1996, p. 21-67.

10 Loving v. Virginia, de 1967, no qual a Corte reputou incompatível com o princípio da igualdade leis de dezesseis estados que proibiam o casamento inter-racial sob o pretexto de preservar a integridade racial de seus cidadãos. Nela, faz-se referência na decisão à doutrina esboçada em Carolene: "...o princípio da igualdade exige que classificações raciais, especialmente suspeitas em leis criminais, sejam submetidas ao mais rígido escrutínio e, se alguma vez tiverem que ser mantidas, deve ser demonstrado que são necessárias para o cumprimento de um objetivo estatal legítimo, independente da discriminação racial que a Décima Quarta Emenda teve por objetivo eliminar". (LOCKHART, 1996, p. 1.181)

11 HORWITZ, 1998, p. 82. 
de 1964, formulou o princípio "um homem, um voto”. Do voto de WARREN:

"O conceito da igual proteção tem sido tradicionalmente visto como exigindo o tratamento uniforme de pessoas que se encontram na mesma situação em relação à ação governamental questionada ou desafiada. No que se refere à alocação da representação legislativa, todos os votantes, como cidadãos de um Estado, encontram-se na mesma situação independentemente de onde moram. Nenhum critério sugerido para a diferenciação entre cidadãos é suficiente para justificar qualquer discriminação em relação ao peso de seus votos a menos que relevante para os propósitos permissíveis da distribuição eleitoral. Como atingir a justa e efetiva representação para todos os cidadãos é o alvo admitido da ordenação eleitoral, nós concluímos que o princípio da igualdade garante a oportunidade de igual participação para todos os votantes nas eleições dos legisladores estaduais. Diluir o peso dos votos em virtude do local de residência viola direitos constitucionais básicos protegidos pela Décima Quarta Emenda assim como discriminações odiosas baseadas em fatores como raça ou status econômico." 12

Trata-se de um caso exemplar da doutrina esboçada em Carolene. Não se podia confiar no processo democrático para reparar a violação da constituição, uma vez que esta também afetava o seu adequado funcionamento. $\bigcirc$ legislador, cuja permanência no cargo dependia da continuidade da má ordenação, não era confiável para repará-la, estando nessa hipótese a autoridade judicial em melhores condições para atuar com a imparcialidade necessária.

Tal entendimento é bem explicitado por WARREN em Kramer v. Union Free School District, 1969, outro caso que envolvia o direito ao voto, mas sobre outra perspectiva:

"Leis que distribuem o sufrágio constituem a fundação de nossa sociedade representativa. Qualquer discriminação injustificada na determinação de quem pode participar em assuntos políticos ou na seleção de agentes públicos mina a legitimidade do governo representativo. Portanto, se uma lei garante o direito de voto a alguns residentes e cidadãos de certa idade e nega a outros, a Corte deve determinar se a exclusão é necessária para promover um interesse estatal sobrepujante.

A presunção de constitucionalidade e a aprovação concedida a classificações 'racionais' em outros tipos de atos legislativos têm por base a suposição de que as instituições governamentais estão estruturadas de forma a representar eqüitativamente todo o povo. Todavia, quando a objeção à lei é de fato objeção desta suposição básica, a suposição não pode mais servir como base para a presunção da constitucionalidade. E a suposição não é menos questionável pelo fato da legislatura que decide quem deve participar dos vários níveis de escolhas políticas é eleita de forma eqüitativa."13

Os casos envolvendo a reordenação de distritos eleitorais foram tidos pelo pró- 
prio EARL WARREN como os mais importantes de seu período na Corte. ${ }^{14}$ É de se reconhecer que a Corte ousou e enfrentou adequadamente o problema ao contrário das cortes anteriores que depositaram esperanças que se mostraram frustradas no próprio processo político viciado.

\section{Liberdade de expressão e outros direitos preferenciais}

OLIVER WENDELL HOLMES, que serviu na Suprema Corte no período de 1902-1932, foi um de seus juízes mais influentes.

Merecem destaque, em particular, suas teorias acerca da liberdade de expressão. Segundo HOLMES, a liberdade de expressão não pode ser restringida nem mesmo quando envolve incitação ou apologia a ações ilegais. Há a necessidade ainda de que discurso da espécie possa efetivamente resultar na ação ilegal. Trata-se do teste denominado clear and present danger formulado inicialmente em Schenk $v$. United States, de 1919:

"A pergunta em cada caso é se as palavras são usadas em circunstâncias tais e de certo caráter que criam um perigo claro e imediato de produzir os males substantivos que o Congresso tem o direito de prevenir. É um problema de proximidade e grau." 15

É apenas, porém, em seu voto dissidente em Abrams v. United States, de 1919, que o teste foi realmente aplicado, tendo
HOLMES se posicionado contra a condenação de seis trabalhadores que haviam proposto greve geral para protestar contra a intervenção dos Estados Unidos na Revolução Russa:

"A luta pela liberdade de expressão parece-me perfeitamente lógica. Se não se têm dúvidas acerca das próprias premissas ou poder e se deseja um certo resultado de todo coração, naturalmente serão expressos os desejos segundo a lei e eliminada toda a oposição. Permitir uma oposição por meio de expressão parece indicar que se acredita que a expressão é impotente, como quando um homem diz que enquadrou o círculo, ou que não importa em absoluto o resultado, ou que se duvida do poder ou das premissas. Mas quando o homem se convence de que o tempo tem destruído muitas crenças em conflito, poderá chegar a acreditar ainda mais nos fundamentos de sua conduta e que o bem definitivo e desejado é melhor alcançado através de um livre intercâmbio de idéias - que o melhor teste para a verdade é o poder do pensamento em ser por si só aceito na competição do mercado de idéias e que a verdade é a única base sobre a qual seus desejos podem ser seguramente atendidos." 16

HOLMES, aliás, juntamente com outro grande juiz do período, LOUIS BRANDEIS, é conhecido como o grande dissenter. Com efeito, sua posição acerca da proteção constitucional à liberdade de expressão era vencida durante seu período na Corte. Somente as Cortes futuras, em es- 
pecial a Corte de Warren, lograram tornar sua posição prevalente.

Duas decisões da Corte de Warren acerca da liberdade de expressão merecem especial destaque: New York Times v. Sullivan, de 1964; e Brandeburg v. Ohio, de 1969.

Na primeira, policiais do Estado do Alabama processaram por danos contra honra o jornal The New York Times por publicar anúncio pago que solicitava auxílio financeiro para defesa de MARTIN LUTHER KING e que continha diversas declarações errôneas quanto a conduta de policiais em relação ao Dr. KING.

A Corte entendeu que a liberdade de expressão em assuntos públicos deveria de todo modo ser preservada. Estabeleceu que a conduta do jornal estava protegida pela liberdade de expressão salvo se provado que a matéria falsa tivesse sido publicada maliciosamente ou com desconsideração negligente em relação à verdade. Do voto condutor do Juiz WILLIAM BRENNAN:

“... o debate de assuntos públicos deve ser sem inibições, robusto, amplo, e pode incluir ataques veementes, cáusticos e, algumas vezes, desagradáveis ao governo e às autoridades governamentais." ${ }^{\prime 7}$

No outro caso, Brandeburg v. Ohio, de 1969, a Corte reverteu a condenação de líder da Klu Klux Klan que havia sido processado por defender a alteração da ordem por meio da violência. Aqui foi adotada, mesmo em relação a discurso absolutamente condenável moralmente, a doutrina estabelecida por HOLMES. A Corte estabeleceu que:

“... as garantias constitucionais de liberdade de expressão e imprensa não permitem que um Estado proíba ou proscreva a defesa do uso da força ou a violação da lei, exceto quando tal defesa é dirigida a incitar ou produzir iminentes ações ilegais e é apta a incitar ou produzir tais ações." ${ }^{18}$

É oportuno notar que os direitos e liberdades fundamentais não podem ser de todo funcionalizadas, ou seja, postas em relação a determinados fins (o que ocorre, parcialmente, no Direito brasileiro com a propriedade que deve atender sua função social). Não é difícil defender o exercício de direitos fundamentais que contam com amplo apoio popular. Os casos difíceis surgem quando os direitos fundamentais entram em colisão com legítimos interesses comunitários. Nesses casos é que as Cortes podem mostrar seu valor, optando fundamentadamente por um e outro. Se é certo que os direitos fundamentais não são absolutos, também é correto que não podem ser sacrificados sempre que colidirem com interesses comunitários, com o que restaria descaracterizada a idéia central do Estado de Direito, de que o indivíduo é um fim em si mesmo, o que gera a obrigação de que seus direitos sejam levados a sério.

Especificamente no que se refere à liberdade de expressão, é necessário 
preservá-la mesmo quando o discurso é desagradável e mesmo ofensivo à maioria da comunidade. Em primeiro lugar, porque nada tolhe em grau mais significativo o desenvolvimento da personalidade humana do que a imposição do silêncio. Em segundo plano, porque a liberdade de expressão é essencial ao adequado funcionamento da democracia, por permitir amplo debate de idéias.

Pressupostos políticos da espécie foram acolhidos pela Suprema Corte, elevando a liberdade de expressão a uma posição preferencial em relação a outros interesses.

Tal posição preferencial foi estendida com peculiaridades a outros direitos e liberdades sempre que estes foram reputados fundamentais. Sob a Corte de Warren foram reputados fundamentais, entre outros, o direito ao voto, o que levou a decisões como as já mencionadas, e a liberdade de locomoção, esta no caso Shapiro v. Thompson, ${ }^{19}$ de 1969 , que bem ilustra a técnica de decisão adotada pela Corte quando envolvido direito reputado fundamental.

Em Shapiro foram invalidadas diversas leis estaduais que negavam prestações estatais de caráter social àqueles que não comprovassem que residiam nas respectivas localidades por pelo menos um ano. Segundo a Corte, a medida restringia a liberdade de locomoção das pessoas pobres e, nessas condições, deveria ser justificada por um interesse público de especial magnitude, não bastando relacioná-la a um objetivo político válido.
A teoria da posição preferencial, nos dizeres de ENRIQUE ALONSO GARCIA:

“... no solo consiste en la afirmación de la supremacía de determinadas cláusulas constitucionales, sino que ello se refleja en el juego de la presunción de constitucionalidad, de forma que es el Estado que tiene que justificar la ley a la que se dota de una especie de presunción de inconstitucionalidad. Paralelamente, la inversión de la carga de la prueba conlleva la necesidad de proveer con una mayor justificación a la ley, con lo que no basta alegar cualquier interés estatal, sino que ese interés debe tener un plus suficiente para sobrepasar al protegido constitucionalmente." 20

direito de privacidade também foi elevado pela Corte a uma posição preferencial. No entanto, tal tema merece capítulo à parte, pois, ao contrário dos direitos já citados, o direito de privacidade não encontra previsão expressa na Constituição norte-americana.

\section{Direito de privacidade}

Conforme dito, o direito de privacidade não encontra previsão expressa no texto da Constituição norte-americana.

Não obstante, em Roe v. Wade, de 1973, a Corte Burger reconheceu, com base no direito de privacidade, que a interrupção da gravidez não poderia ser indistintamente criminalizada. Como foi isso possível?

A origem de Roe e de várias outras decisões, envolvendo o direito de privaci- 
dade, encontra-se na jurisprudência da Corte de Warren.

A Corte de Warren admitiu a possibilidade de reconhecimento de direitos não enumerados na Constituição norte-americana, seja com base na Nona Emenda da Constituição norte-americana, ${ }^{21}$ seja com base nas normas do due process of law e da equal protection of law, ou ainda com base em interpretação construtiva de prescrições constitucionais específicas.

Em Griswold v. Connecticut, ${ }^{22}$ de 1965, ela invalidou lei estadual que proibia a comercialização ou utilização de anticoncepcionais, reconhecendo a existência de um right of privacy (direito de privacidade) não previsto expressamente da Carta de Direitos. O Juiz WILLIAM DOUGLAS argumentou que várias normas constitucionais, como, por exemplo, a que proíbe invasão de domicílio sem ordem judicial ou a que garante o direito a não autoincriminação, criariam "zonas de privacidade" imunes às intervenções do poder público, que deveriam ser estendidas para proteger as decisões tomadas no seio da relação matrimonial, inclusive as relativas à utilização ou não de métodos anticoncepcionais. Em suas memoráveis palavras:

"Os casos antecedentes [casos nos quais a Suprema Corte reconheceu as ditas 'zonas de privacidade'] sugerem que garantias específicas na Carta de Direitos contêm penumbras, formadas por emanações dessas garantias que lhes conferem vida e substância. Várias garantias criam zonas de privacidade. A liberdade de associação contida na penumbra da Primeira Emenda é uma, como nós vimos. A Terceira Emenda, em sua proibição contra a obrigatoriedade de aquartelamento de soldados 'em qualquer casa' em tempos de paz sem o consentimento do dono, é outra faceta desta privacidade. A Quarta Emenda é outra. A Quinta Emenda, em sua cláusula de não-auto-incriminação, habilita o cidadão a criar zona de privacidade que o governo não pode obrigá-lo a dispensar em seu detrimento. A Nona Emenda prevê: 'A enumeração nesta Constituição de certos direitos não deve ser interpretada para denegar ou depreciar outros retidos pelo povo'."23

No mesmo sentido, encontra-se o voto concorrente do Juiz ARTHUR GOLDBERG:

"Minha conclusão, de que ela [a Carta de Direitos] abrange o direito de privacidade na relação matrimonial, embora este não seja mencionado explicitamente na Constituição, tem suporte tanto nas numerosas decisões como na linguagem e história da Nona Emenda, as quais revelam que os Autores da Constituição acreditavam que existiam direitos fundamentais adicionais, protegidos da violação governamental. A Nona Emenda foi professada para silenciar receios expressos de que uma carta de direitos especialmente enumerados poderia

21 A Nona Emenda dispõe expressamente: "A enumeração nesta Constituição de certos direitos não deve ser interpretada para denegar ou depreciar outros retidos pelo povo". Tal norma encontra equivalente no art. $5^{\circ}$, $\S 2^{\circ}$, da Constituição brasileira.

22 LOCKHART, 1996, p. 393-402.

LOCKHART, 1996, p. 395. 
não ser suficientemente ampla para abranger todos os direitos essenciais e que uma menção específica de certos direitos seria interpretada como uma negação de que outros estariam também protegidos." ${ }^{24}$

A Corte foi severamente criticada por esta decisão. Mesmo o liberal HUGO BLACK dela dissentiu, unindo-se ainda ao voto dissidente do Juiz STEWART que expressamente declarou que não podia "encontrar nenhum direito geral à privacidade na Carta de Direitos, em qualquer outra parte da Constituição ou em qualquer caso anteriormente decidido pela Corte". ${ }^{25}$

HUGO BLACK, aliás, era o maior defensor de interpretação literal ou apegada ao texto da Constituição norte-americana. Tal entendimento o elevou à posição de principal defensor da liberdade de expressão, em vista dos termos empregados pela Primeira Emenda da Constituição norte-americana (Congress shall make no law ... abridging the freedom of speech, or of the press). BLACK defendia uma interpretação absolutista de tal dispositivo, argumentando que a referida liberdade não poderia sofrer qualquer espécie de restrição, mesmo frente a outras normas constitucionais ou princípios como o da razoabilidade. $\bigcirc$ constituinte, segundo BLACK, já teria realizado toda a ponderação entre os interesses em jogo. A interpretação de BLACK sobre a primei- ra emenda, conquanto não adotada na íntegra pela Suprema Corte, foi um dos fatores que contribuiu para que a liberdade de expressão fosse guindada a uma posição privilegiada. $^{26}$

Seu entendimento, porém, o impedia de unir-se à Corte no reconhecimento de direitos não enumerados. Interessante notar que o método de interpretação defendido por BLACK e que lhe servia em suas posições majoritariamente liberais é atualmente defendido pelas correntes conservadoras da Suprema Corte que defendem um apego estrito ao texto constitucional. ${ }^{27}$

fato é que não é viável a interpretação da Constituição sem o recurso a elementos fora do texto, o que autoriza atividade mais criativa por parte do juiz constitucional. Com efeito, normas de elevada abstração, como a que garante a liberdade de expressão ou o princípio da igualdade, presentes tanto na Constituição norte-americana como na brasileira, não podem ser interpretadas sem o recurso à doutrina política subjacente ao texto constitucional. Para atribuição de sentido determinado a esses dispositivos é inevitável o recurso a alguma espécie de argumentação moral, como é reconhecido por boa parte da doutrina e jurisprudência norteamericana. DWORKIN, entre outros, defende a leitura moral (moral reading) de tais

24 LOCKHART, 1996, p. 396.

25 LOCKHART, 1996, p. 402.

26 Sobre o papel de BLACK na jurisprudência da Suprema Corte, recomenda-se a leitura de FREYER, 1995, p. 86-105. TONY. Hugo L. Black and the Warren Court in retrospect. In TUSHNET, Mark (Ed.). The Warren Court in historical and political perspective. Charlottesville: University Press of Virginia, 1995, p. 86-105.

27 Por todos, SCALIA, 1997. 
dispositivos..$^{28}$ Obviamente, tal entendimento tem implicações sérias no que se refere ao postulado positivista de separação estrita entre moral e direito. Oferece, também, questionamentos à legitimidade da atividade judicial que, pretensamente, deve ser neutra em relação a valores. Tais questões intrincadas que tocam fundo a teoria do Direito e da natureza da atividade judicial não podem ser aqui tratadas, merecendo reflexões à parte. ${ }^{29}$

As decisões da Corte de Warren sobre o direito de privacidade, entretanto, não foram tão criticadas como suas decisões em casos criminais, estas sim amplamente impopulares, sendo, inclusive, tema das campanhas presidenciais da época, o que se verá a seguir.

\section{Casos criminais}

YALE KAMISAR defende que os casos criminais decididos pela Corte Warren devem ser compreendidos à luz do princípio da igualdade e dos movimentos civis norte-americanos. ${ }^{30}$ A lei criminal nos Estados Unidos, segundo o mesmo autor, era freqüentemente utilizada com propósitos discriminatórios, principalmente nos estados do sul. As decisões da Corte visariam proteger especialmente os direitos dos acusados socialmente vulneráveis.

O exemplo óbvio é Gideon v. Wainright, de 1963, que reconheceu aos acusados perante tribunais estaduais o direito a assistência judiciária provida pelo Estado se não tivessem condições de contratar um advogado. Tal direito era reconhecido pela Sexta Emenda à Constituição norte-americana aos acusados perante cortes federais. Questão que se colocava era se tal direito era extensível às cortes estaduais.

Há que se realizar o esclarecimento de que os direitos previstos nas dez primeiras emendas à Constituição norte-americana destinavam-se originariamente a proteger o cidadão não contra os Estados, mas contra a possível opressão da então criada União Federal. Alguns, como o juiz

28 "A leitura moral propõe que nós todos - juízes, advogados, cidadãos - interpretemos e apliquemos essas normas abstratas segundo 0 entendimento de que elas invocam princípios morais acerca da decência política e justiça." (DWORKIN, 1996, p. 2).

29 Por oportuno, apenas transcreve-se as reflexões de DWORKIN acerca das objeções à teoria da "leitura moral" da Constituição a pretexto de salvaguardar a neutralidade do juiz constitucional: "Políticas constitucionais têm sido confundidas e corrompidas pela pretensão de que os juízes (se ao menos eles não fossem tão sedentos pelo poder) poderiam usar estratégias de interpretação da constituição politicamente neutras. Juízes que aderem a tal pretensão tentam esconder, às vezes de si mesmos, a influência inevitável de suas próprias convicções, e o resultado é uma custosa mendacidade. Os verdadeiros fundamentos da decisão são ocultados do exame legítimo do público e também do valioso debate público. A leitura moral oferece conselho diferenciado. Eu expliquei porque a fidelidade à Constituição e ao Direito exige que os juízes façam julgamentos contemporâneos de moralidade política, e ela, portanto, incentiva a exibição aberta dos verdadeiros fundamentos do julgamento, na esperança de que os juízes irão construir argumentos francos de princípio que permitam ao público a unir-se ao debate. (...) Então, é claro que a leitura moral incentiva advogados e juízes a ler uma constituição abstrata sob a luz do que eles entendem que seja justo. De que outra forma eles poderiam responder as questões morais que uma constituição aberta lhes coloca? (...) O texto e a integridade atuam como limites importantes, como estive enfatizando durante esta discussão. Mas apesar destes limites moldarem e limitarem o impacto de convicções acerca da justiça, eles não podem eliminar este impacto. A leitura moral insiste, entretanto, que esta influência não é prejudicial e desde que as convicções forem identificadas e defendidas honestamente por argumentos apropriados de princípio - eu enfatizo - e não apenas magros slogans ou velhas metáforas". (DWORKIN, 1996, p. 37)

KAMISAR, 1996, p. 116-158. 
HUGO BLACK, defendiam a teoria da incorporação total, segundo a qual a Décima Quarta Emenda, esta adotada logo após a guerra de secessão e dirigida contra os Estados, tinha entre seus propósitos, através de suas normas abstratas da equal protection of law e due process of law, tornar oponíveis aos Estados os direitos previstos nas dez primeiras emendas. Tal teoria jamais foi acolhida expressamente pela Suprema Corte. Entretanto, a Suprema Corte, notadamente a Corte de Warren, passou a realizar uma incorporação seletiva destes direitos, sempre que os reputava fundamentais e como tais inerentes ao due process of law.

Em Gideon, o direito reconhecido pela Sexta Emenda foi reputado pela Corte de Warren essencial para assegurar um julgamento justo e como tal também oponível aos Estados, sendo, aliás, revertido precedente da própria Suprema Corte em sentido oposto (Bretts v. Brady, de 1942).

Mapp v. Ohio, de 1961, foi outra decisão tomada na esteira desse entendimento, sendo estendido aos Estados a exclusionary rule (vedação de provas ilícitas em processo) que a Suprema Corte havia imposto às autoridades federais em Weeks v. United States, de 1914. Da mesma forma, a Corte reverteu precedente em sentido contrário (Wolf v. Colorado, de 1949). Do voto condutor do Juiz CLARK, extrai-se o seguinte trecho no qual faz referência a célebre voto vencido do Juiz BRANDEIS em Olmstead v. United States, de 1928:

"Há aqueles que dizem, como o Juiz CARDOSO, que em virtude de nos- sa constitutional exclusionary doctrine 'os criminosos podem sair livres porque o policial atrapalhou-se.' 'People v. Defore', 241 N.Y., at 21, 150 N. E., at 587. Em alguns casos isso será indubitavelmente o resultado. Mas, como foi dito em Elkins, 'há outra consideração - o imperativo da integridade da justiça'. 364 U.S., at 222. O criminoso sai livre, se assim deve ser, mas é o Direito que o deixa livre. Nada pode destruir um governo mais rapidamente que seu insucesso em observar suas próprias leis, ou pior, sua desconsideração da garantia de sua existência. Como o Sr. Juiz BRANDEIS, divergindo, disse em Olmstead v. United States, 277 U.S. 438, 485 (1928): 'Nosso Governo é o mestre poderoso e onipresente. Para o bem ou para o mal, ele ensina todo o povo pelo seu exemplo. (...) Se o Governo torna-se infrator da lei, cria ele próprio o desrespeito à mesma, incita cada um a tornar-se sua própria lei e, portanto, à anarquia."'31

MAPP foi severamente criticada como favorecendo indevidamente os criminosos. Entretanto, nenhuma outra decisão criminal da Corte de Warren foi tão criticada como Miranda v. Arizona, de 1966.

Em Miranda, a decisão da Corte visou garantir o real exercício pelo acusado da proteção contra a auto-incriminação prevista na Quinta Emenda à Constituição norte-americana e coibir a extração forçada, por meios físicos ou psicológicos, de confissões em casos criminais. Outra preocupação da Corte foi de estabelecer regras claras para os interrogatórios policiais, evitando que as cortes inferiores tivessem que 
examinar as circunstâncias de caso a caso para verificar se as declarações do acusado foram prestadas ou não voluntariamente:

"Nós concluímos que sem salvaguardas próprias o processo de interrogatório sob custódia de pessoas suspeitas ou acusadas de crime contém pressões coercivas inerentes que operam para minar a vontade individual de resistir e para compeli-lo a falar quando ele não o faria livremente em outras circunstâncias. Para combater essas pressões e para permitir uma oportunidade ampla de exercício do privilégio contra a autoincriminação, o acusado deve ser adequadamente e efetivamente informado de seus direitos e o exercício desses direitos deve ser completamente honrado." 32

A preocupação em garantir principalmente o direito dos acusados indigentes, pouco conscientes de seus direitos, relaciona "Miranda" com o princípio da equal protection of law:

"O privilégio contra a autoincriminação assegurado pela Constituição aplica-se a todos os indivíduos. A necessidade de advogado para proteger o privilégio existe para o indigente assim como para o rico.

\section{(...)}

A advertência do direito a um advogado seria vazia se não colocada em termos que transmitam ao indigente $-\mathrm{a}$ pessoa mais freqüentemente submetida a interrogatórios - a informação de que ele também tem o direito à presença de um advogado." ${ }^{33}$

Assim, declarações incriminatórias obtidas em interrogatório policial só poderiam ser admitidas como prova se o acusado fosse previamente informado de seu direito de permanecer calado, de que qualquer coisa que dissesse poderia ser usada contra ele, de que teria o direito à presença de um advogado, de que se não pudesse pagar o advogado, teria direito a um fornecido pelo Estado.

que surpreende em Miranda é o grau de criatividade da interpretação desenvolvida pela Suprema Corte. Afinal, tendo por base dispositivo que estabelece simplesmente que ninguém poderá ser obrigado a depor contra si mesmo, ela elaborou uma série de regras para garantir o exercício do direito de vedação à autoincriminação, assumindo função praticamente legislativa.

$\mathrm{O}$ fato é que a Corte agiu bem. Reconhecido direito fundamental, deve a jurisdição constitucional fazer o necessário para garanti-lo sem a preocupação excessiva com distinções acadêmicas. ${ }^{34}$

Miranda, coincidindo, porém, com uma época de escalada de crimes, foi uma das menos populares decisões da Corte, ser-

32 WEINREB, 1997, p. 632.

33 WEINREB, 1997, p. 535.

34 Talvez a atitude da Corte possa servir de exemplo aos juízes e tribunais brasileiros que, no exercício do controle de constitucionalidade, apelam para a vetusta distinção entre a atuação judicial como "legislador negativo" e a atuação como "legislador positivo", negando, salvo raras exceções, a possibilidade de reparação da violação à Constituição no último caso. A ver do 
vindo de tema para a campanha presidencial de NIXON em 1962, que servia-se do slogan lei e ordem e propunha a revisão das decisões criminais da Corte de Warren.

Atualmente, a hostilidade a Miranda dissipou-se, não havendo maiores questionamentos acerca da decisão. Estudo, aliás, de comitê especial da American Bar Association concluiu que a maioria dos envolvidos em casos criminais, juízes, promotores e oficiais da polícia, concordavam que Miranda não oferecia dificuldades para a aplicação da lei penal. ${ }^{35}$

Paradoxalmente, há quem, atualmente, critique Miranda por não ter ido além, exigindo maiores garantias aos acusados em casos criminais, como a gravação do interrogatório policial. ${ }^{36}$

A posterior aceitação de Miranda contribuiu para que a decisão jamais fosse revertida. Aliás, a maioria das conquistas da Corte de Warren, apesar da ameaça de Cortes sucessivamente mais conservadoras, não foi revertida. É certo, contudo, que tais Cortes não contribuíram para expansão em larga medida de tais conquistas.

\section{Considerações finais}

\author{
A reação à Corte de Warren não \\ tardou.
}

Sucessivas indicações de juízes conservadores por presidentes republicanos (NIXON e REAGAN) culminaram por afastar a Suprema Corte do caminho iniciado por WARREN.

Interessante, porém, notar que a maioria das decisões da Corte não foi revertida, fazendo ainda parte do Direito norte-americano.

Para tanto, contribuiu a permanência, mesmo após a retirada de WARREN,

autor, trata-se de apego à teoria kelseniana da jurisdição constitucional que não faz sentido. Com efeito, o juiz, no exercício do controle de constitucionalidade, invade invariavelmente área reservada ao legislador, tanto se invalidar ato legislativo como se suprir vazio legislativo. Não existe qualquer razão política subjacente a justificar o tratamento diferenciado em um e outro caso. Aliás, a interferência parece ser maior no primeiro caso, quando o juiz censura expressamente ato legislativo, sobrepondo sua interpretação da Constituição à interpretação legislativa, do que quando atua supletivamente, censurando não um ato, mas uma omissão. É o caso de destacar que outras Cortes Constitucionais, como a italiana e francesa, têm como sindicáveis e reparáveis omissões inconstitucionais, não havendo notícia de que tal comportamento tenha levado à espécie de "ditadura judicial" na Itália ou França. Como exemplo, podem ser citadas as conhecidas decisões interpretativas aditivas da Corte Constitucional italiana e do Conselho Constitucional francês sobre as quais escreve THIERRY DI MANNO: "Com efeito, mesmo que o controle de constitucionalidade das omissões do legislador não esteja previsto expressamente pela Constituição, o juiz constitucional que é provocado a conhecer normas legislativas não pode deixar de confrontar-se com esta problemática, uma vez que é possível, como vimos, tratar uma omissão legislativa como uma norma legislativa negativa. $\mathrm{E}$ de fato, confrontadas com esta questão, a Corte Constitucional italiana e o Conselho Constitucional francês têm recorrido à técnica da interpretação aditiva que permite adotar formas de decisões adaptadas ao controle e a reparação de omissões legislativas contrárias à Constituição". (DI MANNO, 1994, p. 238). Isso não significa que não existem limites à atuação da jurisdição constitucional. Tais limites, entretanto, não devem ser procurados em distinções mecânicas, mas sim na solução de questões interpretativas específicas. O juiz constitucional em Estado Democrático de Direito deve assumir o firme compromisso de tornar realidade a Constituição, principalmente as normas de direito fundamental. Não se justifica, em nenhuma hipótese, a falta de cumprimento desta tarefa com base em distinções meramente "semânticas" e sem correspondência com alguma justificativa política. Para exame mais aprofundado desta questão, vide MORO, 2000.

KAMISAR, 1996, p. 123. 
de vários juízes liberais na Corte, bem como a popularidade de algumas de suas decisões e a progressiva dissipação da hostilidade contra outras menos populares.

Em suma, apesar das indicações destinadas à reversão da jurisprudência da Corte de Warren, as conquistas desta até o momento permanecem em vigor.

As indicações conservadoras, entretanto, não propiciaram a extensão de algumas destas conquistas nem evolução mais significativa da linha jurisprudencial da Corte de Warren.

Não obstante, à Corte de Warren, por suas decisões e pela influência na jurisprudência e doutrina norte-americana, e mesmo mundial, está assegurado um local no panteão das grandes cortes judiciais.

O seu grande mérito foi ter a ousadia necessária para enfrentar os problemas constitucionais norte-americanos de seu tempo, sem ceder frente a obstáculos artificiais.

Não é possível deixar de fazer um paralelo em relação à produção de nosso Supremo Tribunal Federal.

Supremo, apesar do sistema de nomeação de juízes que, na prática, não funciona, pela inexistência de controle efetivo pelo Congresso ou pela sociedade civil sobre as escolhas do Presidente da República, faça-se justiça, já deu mostras suficientes de sua independência frente ao Executivo, como ilustra, aliás, a recente e rumorosa decisão proferida quanto aos expurgos dos saldos das contas vinculadas ao FGTS.
Entretanto, é necessário também reconhecer que a jurisprudência do Supremo Tribunal Federal frustrou várias expectativas daqueles que esperavam uma defesa mais robusta dos direitos fundamentais e da Constituição Federal após o fim da ditadura militar. A título ilustrativo pode ser citada a recusa do Supremo em submeter a crivo judicial mais rigoroso a edição descontrolada de medidas provisórias, a jurisprudência nulificadora do mandado de injunção, a falta de qualquer medida efetiva para concretização de determinados direitos fundamentais como o salário mínimo, o direito a greve do servidor público e os juros constitucionais.

É certo que o juiz constitucional não deve desconhecer seus limites. Quanto mais intensa a atividade da jurisdição constitucional, maiores serão os questionamentos acerca da legitimidade da interferência judicial em regime democrático.

A Corte de Warren prova, todavia, que algum ativismo judicial pode mostrarse benéfico, contribuindo não para o enfraquecimento da jurisdição constitucional e da democracia, mas para o seu próprio fortalecimento.

É viável a defesa da jurisdição constitucional e de parte de suas decisões com base em argumentos que apelam para o próprio regime democrático. ${ }^{37}$

O que enfraquece em realidade a jurisdição constitucional, provocando questionamentos acerca de sua necessidade e legitimidade, é a recusa das Cortes no 
enfrentamento dos problemas constitucionais mais sérios.

EARL WARREN se opunha à postura de restrição judicial, que, aliás, predominava na Suprema Corte antes de sua nomeação. Quando de entrevista em sua retirada, teve oportunidade de defender expressamente seu posicionamento. "Eu acredito", declarou, "que esta Corte ou qualquer corte devem exercitar as funções do ofício até o limite de suas responsabilidades". Segundo WARREN, a postura restritiva significava que "por longa data, estávamos [a Suprema Corte] varrendo para debaixo do tapete uma grande parte de problemas básicos para a sociedade norte-americana. Nós falhamos em encará-los, eles se amontoaram sobre nós, e agora estão provocando desacordos e controvérsias de todos os tipos". ${ }^{38}$ A história da Corte de Warren mostra que seu chefe comportouse segundo seu entendimento.

Roga-se para que o exemplo seja seguido. Daí a necessidade de que a história seja contada e a origem deste artigo.

\section{Referências bibliográficas}

ALONSO GARCÍA, Enrique. La interpretación de la Constitución. Madrid: Centro de Estudos Constitucionales, 1984.

BRENNAN JR., William J. "A personal remembrance". In SCHWARTZ, Bernard (Ed.) The Warren Court: a retrospective. Oxford: Oxford University Press, 1996, p. 8-11.

CATTONI, Marcelo. Devido processo legislativo: uma justificação democrática do controle jurisdicional de constitucionalidade das leis e do pro- cesso legislativo. Belo Horizonte: Mandamentos, 2000.

CHAMBERS, Julius L. Race and equality: the still unfinished business of the Warren Court. In SCHWARTZ, Bernard (Ed.) The Warren Court: a retrospective. Oxford: Oxford University Press, 1996, p. 21-67.

DI MANNO, Thierry. Le juge constitutionnel et la technique des décisions "interprétatives" en France et en Italie. Paris: Economica, 1994.

DWORKIN, Ronald. A matter of principle. Cambridge: Harvard University Press, 1985.

.Freedom's Law: the moral reading of the american Constitution. Cambridge: Harvard University Press, 1996. Fontes, 1999.

. O império do Direito. São Paulo: Martins . Uma questão de princípio. São Paulo: Martins Fontes, 2000.

. Sovereign virtue: the theory and practice of equality. Cambridge: Harvard University Press, 2000.

ELY, John Hart. Democracy and distrust: a theory of judicial review. 11. imp. Cambridge: Harvard University Press, 1995.

FREYER, Tony. Hugo L. "Black and the Warren Court in retrospect". In TUSHNET, Mark (Ed.). The Warren Court in historical and political perspective. Charlottesville: University Press of Virginia, 1995, p. 86-105.

HABERMAS, Jürgen. Direito e democracia: entre facticidade e validade. Rio de Janeiro: Tempo Brasileiro, 1997.

HORWITZ, Morton F. The Warren Court and the pursuit of Justice. New York: Hill and Wang, 1998.

KAMISAR, Yale. "The Warren Court and criminal justice". In SCHWARTZ, Bernard (Ed.) The Warren Court: a retrospective. Oxford: Oxford University Press. 1996, p. 116-158. 
LOCKHART, William B.; KAMISAR, Yale; CHOPER, Jesse H.; SHIFFRIN, Steven H.; FALLON JR., Richard H. Constitucional law: cases-comments-questions. 18. ed., St. Paul, Minn.: West Pub., 1996.

MORO, Sergio Fernando. Desenvolvimento e efetivação judicial das normas constitucionais. São Paulo: Max Limonad, 2001.

RODRIGUES, Leda Boechat. A corte suprema e o direito constitucional americano. Rio de Janeiro: Forense, 1958.

SCALIA, Antonin. A matter of interpretation: Federal Courts and the Law. Princeton: Princenton University Press, 1997.
SCHWARTZ, Bernard (ed.) The Warren Court: a retrospective. Oxford: Oxford University Press, 1996.

. A book of legal lists: the best and worst in american law. Oxford: Oxford University Press, 1997.

TUSHNET, Mark (Ed.). The Warren Court in historical and political perspective. Charlottesville: University Press of Virginia, 1993.

WEINREB, Lloyd L. (Ed.) Leading constitutional cases on criminal justice. Westbury: Foundation Press, 1997.

WOLFE, Chrsitopher. La transformacion de la interpretacionl constitucional. Madrid: Civitas, 1991. 